\title{
Article \\ Diffusion Bonding of Al-Mg-Si Alloy and 301L Stainless Steel by Friction Stir Lap Welding Using a Zn Interlayer
}

\author{
Ji-Hong Dong ${ }^{1,2,3}$, Hua Liu ${ }^{4}$, Shu-De Ji ${ }^{4, *}$, De-Jun Yan ${ }^{5, *}$ and Hua-Xia Zhao ${ }^{3}$ \\ 1 Beijing Institute of Petrochemical Technology, Beijing 102617, China; dongjihong2021@163.com \\ 2 Beijing Academy of Safety Engineering and Technology, Beijing 102617, China \\ 3 AVIC Manufacturing Technology Institute, Beijing 100024, China; zhaohuaxiapaper@163.com \\ 4 College of Aerospace Engineering, Shenyang Aerospace University, Shenyang 110136, China; \\ LH1930375157@163.com \\ 5 Guangdong Key Laboratory of Enterprise Advanced Welding Technology for Ships, \\ CSSC Huangpu Wenchong Shipbuilding Company Limited, Guangzhou 510715, China \\ * Correspondence: superjsd@163.com (S.-D.J.); yandejun_2003@163.com (D.-J.Y.)
}

Citation: Dong, J.-H.; Liu, H.; Ji, S.-D.; Yan, D.-J.; Zhao, H.-X. Diffusion Bonding of Al-Mg-Si Alloy and 301L Stainless Steel by Friction Stir Lap Welding Using a Zn Interlayer. Materials 2022, 15, 696. https:// doi.org/10.3390/ma15030696

Academic Editors: Long Wan and Yuqing Mao

Received: 23 November 2021 Accepted: 20 December 2021 Published: 18 January 2022

Publisher's Note: MDPI stays neutral with regard to jurisdictional claims in published maps and institutional affiliations.

Copyright: (C) 2022 by the authors. Licensee MDPI, Basel, Switzerland. This article is an open access article distributed under the terms and conditions of the Creative Commons Attribution (CC BY) license (https:// creativecommons.org/licenses/by/ $4.0 /)$.

\begin{abstract}
Friction stir lap welding (FSLW) is expected to join the hybrid structure of aluminum alloy and steel. In this study, the Al-Mg-Si aluminum alloy and 301L stainless steel were diffusion bonded by FSLDW with the addition of $0.1 \mathrm{~mm}$ thick pure $\mathrm{Zn}$ interlayer, when the tool pin did not penetrate the upper aluminum sheet. The characteristics of lap interface and mechanical properties of the joint were analyzed. Under the addition of $\mathrm{Zn}$ interlayer, the diffusion layer structure at lap interface changed from continuous to uneven and segmented. The components of the diffusion layer were more complex, including Fe-Al intermetallic compounds (IMCs), Fe-Zn IMCs and Al-Zn eutectic. The largely changed composition and thickness of uneven and segmented diffusion layer at the lap interface played a significant role in the joint strength. The tensile shear load of $\mathrm{Zn}$-added joint was $6.26 \mathrm{kN}$, increasing by $41.3 \%$ than that of Zn-not-added joint. These two joints exhibited interfacial shear fracture, while the $\mathrm{Zn}$ interlayer enhanced the strength of diffusion bonding by extending the propagation path of cracks.
\end{abstract}

Keywords: friction stir lap welding; dissimilar metals; diffusion layer; Zn interlayer; mechanical properties

\section{Introduction}

Steels and 6xxx series aluminum alloys play a vital role in the modern transportation manufacturing [1,2]. With the increasing demand for lightweight products in rail transit, automobile and ship manufacturing, the hybrid structure of the aluminum alloy and the steel $(\mathrm{Al} /$ steel) is expected to replace a single steel structure [3,4]. At present, the lap structure of dissimilar metals can be joined by transient liquid phase bonding, fusion welding, brazing and solid-state welding [5-8]. However, the transient liquid phase bonding requires long time to obtain a good joining. Due to the high heat input during fusion welding, amounts of undesirable intermetallic compounds (IMCs) are easily generated at the Al/steel interface, which greatly reduces the mechanical properties of the $\mathrm{Al} /$ steel joint. Although brazing has the advantages of a smaller joint deformation and less IMCs generation than fusion welding, defects such as slags and porosities are easily produced because of the filler material. In order to improve the reliability of the welded joint, solid-state welding is preferred for $\mathrm{Al} /$ steel dissimilar metals [9].

Friction stir welding (FSW), as a mature solid-state joining technology, has achieved the joining of $\mathrm{Al} /$ steel $[10,11]$. Moreover, FSW characterized by low heat input and severe material plastic deformation can improve the mechanical properties of the $\mathrm{Al}$ / steel joint [12]. Compared with brazing and fusion welding, friction stir lap welding (FSLW) can effectively reduce IMCs at the lap interface of the Al/steel joint [13,14]. Kar et al. [15] investigated the effects of rotating speeds on the interfacial microstructures and mechanical properties of a $6061 \mathrm{Al} / \mathrm{mild}$ steel joint. At $1700 \mathrm{rpm}$, the joint structure in the weld containing 
mechanical mixing, fine particles and an intercalated interface without defects provided better mechanical properties. Moreover, Mahto et al. [16] studied the effects of welding and rotating speeds on the mechanical properties of AA6061 Al/AISI 304 steel, and the higher joint strength was obtained with the lower $w / v$ due to the thickness reduction of IMCs layer.

In the study of FSW, artificial intelligence tools are used to maximize the joint strength by optimize the welding process parameter combination, such as adaptive neuro-fuzzy inference system, random vector functional link [17-19]. Generally speaking, how to obtain a sound welding joint with high quality needs to be investigated prior to using the artificial intelligence tools. Adding the metal interlayer at the lap interface of the dissimilar materials joint can directly affect the atom diffusion and the growth of IMCs [20,21], thereby adjusting the interface structure. In the study of Ahmed et al. [22], joints of aluminum and Zn-coated steel exhibited the higher strength at all welding parameters, showing the beneficial effect of the Zn coating on the joint strength. Zheng et al. [21] welded $6061 \mathrm{Al}$ to 316 stainless steel using the $\mathrm{Zn}$ interlayer. Under the addition of the $\mathrm{Zn}$ interlayer, the thin steel- $\mathrm{Zn}$ mixing layer structure was discovered at the interface, and no IMCs interlayer was discovered at the interface, thereby obtaining the high-strength joint. Appropriate application of interlayer can significantly bring benefit to the microstructural and mechanical properties of the $\mathrm{Al} /$ steel joint [23].

Meanwhile, the relative position between the tool pin tip and the upper steel surface of the $\mathrm{Al} /$ steel FSLW joint is another critical factor, which attracts the attention of scholars. When the rotating tool inserts into the steel sheet, the interface geometry induced by the mechanical stirring from the rotating tool influences the loading capacity of the $\mathrm{Al} /$ steel lap joint $[11,15,24]$. In order to avoid the hook of interface, Huang et al. [25] proposed an enlarged pin head with circumferential notches to obtain the ultra-strong interface of the 6082-T6 Al and QSTE340TM steel joint. They found that the effective interfacial width was increased, and the joint strength was improved by this special tool. Haghshenas et al. [26] used friction stir-induced diffusion bonding for joining 5754 Al to DP600 steel obtained a relatively flat lap interface when the rotating tool did not contact the steel surface, because the intense thermo-mechanical deformation only occurred in the upper aluminum alloy sheet.

In this study, the diffusion bonding was adopted to realize the joining of $\mathrm{Al} / \mathrm{steel}$ dissimilar metals by friction stir lap welding, and the Zn interlayer was simultaneously added to improve interface structure. With the addition of $0.1 \mathrm{~mm}$ thick pure Zn interlayer, the Al-Mg-Si aluminum alloy and 301L austenitic stainless steel as base metals (BMs) were used for FSLW. The effect of $0.1 \mathrm{~mm}$ pure $\mathrm{Zn}$ interlayer on lap interface structure and mechanical properties of the $\mathrm{Al} /$ steel joint were investigated in detail.

\section{Materials and Methods}

In the experiments, the upper and lower BMs were rolled Al-Mg-Si alloy sheets and 301L stainless steel sheets with the size of $230 \mathrm{~mm} \times 120 \mathrm{~mm} \times 2 \mathrm{~mm}$. After X-ray fluorescence and mechanical property tests, the chemical compositions and mechanical properties of two BMs are shown in Tables 1 and 2, respectively. Before welding, the welded region was rubbed with the 1000\# sandpaper, and then the sheets were cleaned with absolute ethanol. The FSW-3LM-4012 FSW machine was used, and the sheets were fixed on a specially designed fixture before welding (Figure 1a). As shown in Figure 1c, the weld length was $200 \mathrm{~mm}$, and the width of overlapping area was $50 \mathrm{~mm}$. The welding tool rotated counterclockwise and moved along the weld centerline. The welding direction was parallel to the rolling direction of BMs. 
Table 1. Chemical compositions and mechanical properties of Al-Mg-Si aluminum alloy.

\begin{tabular}{ccccccccccc}
\hline & \multicolumn{4}{c}{ Chemical Composition(wt. \%) } & \multicolumn{4}{c}{ Mechanical Properties } \\
\hline Si & $\mathbf{M g}$ & $\mathbf{C r}$ & $\mathbf{Z n}$ & $\mathbf{C u}$ & $\mathbf{M n}$ & $\mathbf{T i}$ & $\mathbf{A l}$ & Tensile Strength & Hardness & Elongation \\
\hline 0.08 & 2.62 & 0.19 & 5.81 & 1.59 & 0.01 & 0.02 & Bal. & $355.9 \mathrm{MPa}$ & $99.4 \mathrm{Hv}$ & $7 \%$ \\
\hline
\end{tabular}

Table 2. Chemical compositions and mechanical properties of 301L stainless steel.

\begin{tabular}{cccccccccc}
\hline & \multicolumn{4}{c}{ Chemical Composition(wt. \%) } & \multicolumn{3}{c}{ Mechanical Properties } \\
\hline $\mathbf{C}$ & $\mathbf{N}$ & $\mathbf{S i}$ & $\mathbf{M n}$ & $\mathbf{N i}$ & $\mathbf{C r}$ & Fe & Tensile Strength & Hardness & Elongation \\
\hline 0.03 & 0.2 & 1.00 & 2.00 & 6.00 & 16.00 & Bal. & $864.4 \mathrm{Mpa}$ & $243.2 \mathrm{Hv}$ & $72 \%$ \\
\hline
\end{tabular}
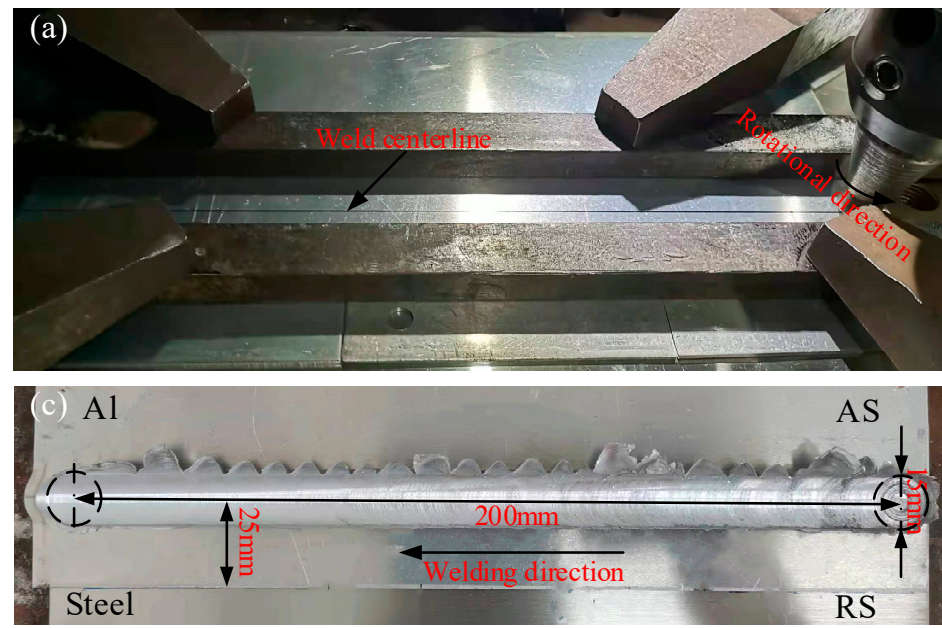

Figure 1. (a) welding process; (b) welding tool; (c) weldment.

The welding tool adopted in the experiments was shown in Figure 1b, and the tapered pin made by the W-Re alloys. The shoulder diameter was $15 \mathrm{~mm}$ and the pin length was $1.7 \mathrm{~mm}$. The plunge depth of shoulder was $0.15 \mathrm{~mm}$, so the distance between the pin tip and the bottom surface of aluminum alloy sheet was $0.15 \mathrm{~mm}$. Therefore, the welding tool almost no wear. Besides, the rotating speed was $1600 \mathrm{rpm}$, the welding speed was $20 \mathrm{~mm} / \mathrm{min}$, and tool tilting angle was $2^{\circ}$, which were selected according to the reported literatures $[16,27,28]$.

After welding, the specimens for metallographic observation and tensile shear tests were first cut by the wire-electrode cutting machine, and the cut direction was perpendicular to the welding direction. The metallographic specimens were polished by MP-1 polishing machine after metallographic sandpapers rubbing with sizes of 180\#, 400\#, 800\#, 1200\#, and 2000\#. Then Keller reagent $\left(5 \mathrm{~mL} \mathrm{HNO}_{3}+1.5 \mathrm{~mL} \mathrm{HCl}+1 \mathrm{~mL} \mathrm{HF}+95 \mathrm{~mL} \mathrm{H} \mathrm{H}_{2} \mathrm{O}\right)$ was used to etched metallographic specimens. The Olympus-GX51 optical microscope was used to observe the micrographs of joints, and the microhardness was measured by the HVS-1000 tester with a $20 \mathrm{~N}$ load for a dwell time of $10 \mathrm{~s}$. According to the standard of ISO 4136, at the room temperature, the tensile shear test was executed by the 5982 universal electronic material-testing machine with the loading speed of $2 \mathrm{~mm} / \mathrm{min}$. In order to reduce the experimental error, three tensile shear specimens were tested for each set of process parameters, and the mean values were used as the ultimate tensile shear load to evaluate the tensile shear strength of joints [16,29]. The Olympus-GX51 optical microscope was used to observe the joint fracture path. The SU3500 machine with scanning electron microscope (SEM) was used to observe the lap interface. And the element diffusion at the lap interface was also analyzed by energy disperse spectroscopy (EDS). 


\section{Results and Discussion}

\subsection{Cross Section Feature and EDS Analysis}

The cross section of the joint with $0.1 \mathrm{~mm} \mathrm{Zn}$ interlayer is shown in Figure 2. The material experiences the uneven thermal mechanical cycle, and therefore the aluminum alloy of the joint is divided into different zones including stir zone (SZ), thermo-mechanically affected zone (TMAZ), and heat affected zone (HAZ). The lap interface is well formed, and no volume defects such as holes appear in the SZ. Because the tool pin does not penetrate the steel sheet during welding, the obvious microstructure change does not occur in the steel surface. The bonding of lap interface mainly depends on the metallurgical bonding between aluminum alloy, steel, and $\mathrm{Zn}$. During welding, the welding tool stirs and then drives the plasticized aluminum alloy to violently flow down toward the lap interface, which has an active effect on the diffusion bonding at the lap interface due to an extra pressure given by the material flow. Therefore, there are no area defects suck as kissing bond appearing in the $\mathrm{Al} /$ steel lap interface, as shown in Figure 2. Moreover, the lap interface of steel side is horizontal because the tool pin does not penetrate the steel sheet during welding and the steel has the relatively high melting point. Due to the mechanical stirring and friction heat from the stirring tool, the $\mathrm{Zn}$ material at the lap interface below the tool shoulder is liquefied and extruded, and then flows to the outside of HAZ. Meanwhile, under the direct stirring of welding tool, the aluminum material is driven to the space occupied by the original $\mathrm{Zn}$ interlayer. Therefore, different from the lap surface of steel side, the lap interface of aluminum side presents a curved morphology (Figure 2).

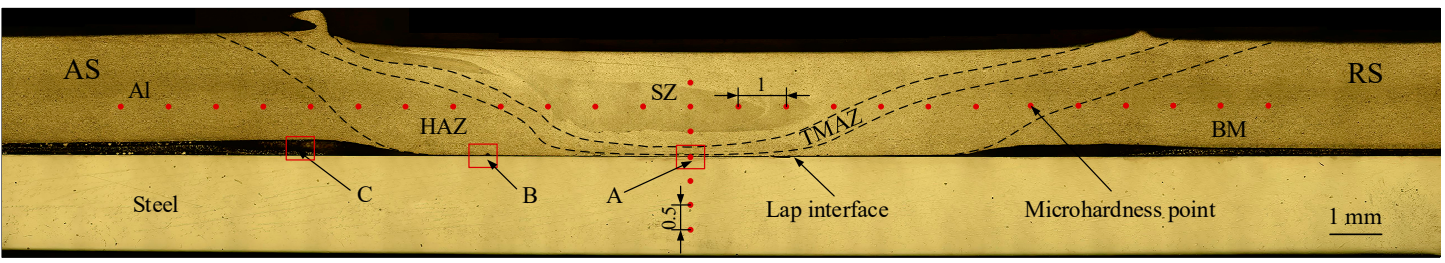

Figure 2. Cross section of the joint with $0.1 \mathrm{~mm} \mathrm{Zn} \mathrm{interlayer.}$

The red squares marked in Figure 2 are selected to further investigate the interface microstructure of the $\mathrm{Al} /$ steel joint. The same locations of $\mathrm{Zn}$-not-added joints were used as the comparison. Figure 3 shows the interface microstructure and EDS analysis of region A, which is at the center of the two joints. The addition of $\mathrm{Zn}$ interlayer has an active effect on the interfacial bonding. In Figure 3a, the maximum thickness of diffusion layer composed of Fe-Al IMCs (abbreviated as Fe-Al IMCs layer) is $4.6 \mu \mathrm{m}$. The formation of IMCs at the interface can make the $\mathrm{Al} /$ steel joint realize metallurgical joining. However, the excessive IMCs can lead to the stress concentration, causing the initiation and propagation of cracks, which reduces the joint bearing capacity. Compared to the study of Mahto et al. [16], the maximum thickness of Fe-Al IMCs layer in this study is reduced. Movahedi et al. [30] also found that there was no adverse effect on the joint quality when the thickness of Fe-Al IMC layer was less than $2 \mu \mathrm{m}$. Comparing Figure 3a,b, it is known that when Zn interlayer is added, the maximum thickness of IMCs layer is reduced from $4.6 \mu \mathrm{m}$ to $1.4 \mu \mathrm{m}$. This phenomenon shows that the addition of $\mathrm{Zn}$ interlayer is conducive to further thinning Fe-Al IMCs layer at the lap interface in the joint center of Al/steel by FSLW diffusion bonding, which is good for the improvement of joint strength when the thickness of IMCs layer is reasonable.

Figure $3 c, d$ are EDS analysis of region A of these two joints respectively. Under the selected welding parameters, the welding heat input is adequate. Therefore, the $\mathrm{Zn}$ interlayer whose melting point is $420{ }^{\circ} \mathrm{C}$ is melted into liquid phase. Given that region A experiences the forging effect from the stirring tool, the liquid-phase Zn flows toward both sides along the interface gap between the two sheets, and then a new $\mathrm{Al} /$ steel interface is formed at region A. Under the combined action of pressure and temperature, the interdiffusion of $\mathrm{Al}$ and Fe atoms occurs at the interface and then Fe-Al IMCs are formed. 
Especially of note, combining the element analysis by EDS line scanning in Figure 3e,f, Zn content of the interface at region $\mathrm{A}$ of the $\mathrm{Zn}$-added joint is extremely low, which reveals that a lot of $\mathrm{Zn}$ liquid is out of the welding center. Certainly, due to the sufficient flow of liquid $\mathrm{Zn}$ by the driving of the stirring tool, there is not enough time for $\mathrm{Zn}$ atoms to diffuse to the sides of aluminum alloy and steel. Therefore, only Fe-Al IMCs is formed at the lap interface in region A, as shown in Figure 3d,f. During diffusion bonding of Al/steel FSLW, the plasticization degree of aluminum material is higher than that of steel, so the liquid phase of Zn can carry more Al element to flow out of region A. Therefore, compared to the Zn-not-added joint (Figure 3c), region A of the Zn-added joint (Figure 3d) has the more intense diffusion degree of Fe atoms to the side of aluminum alloy.

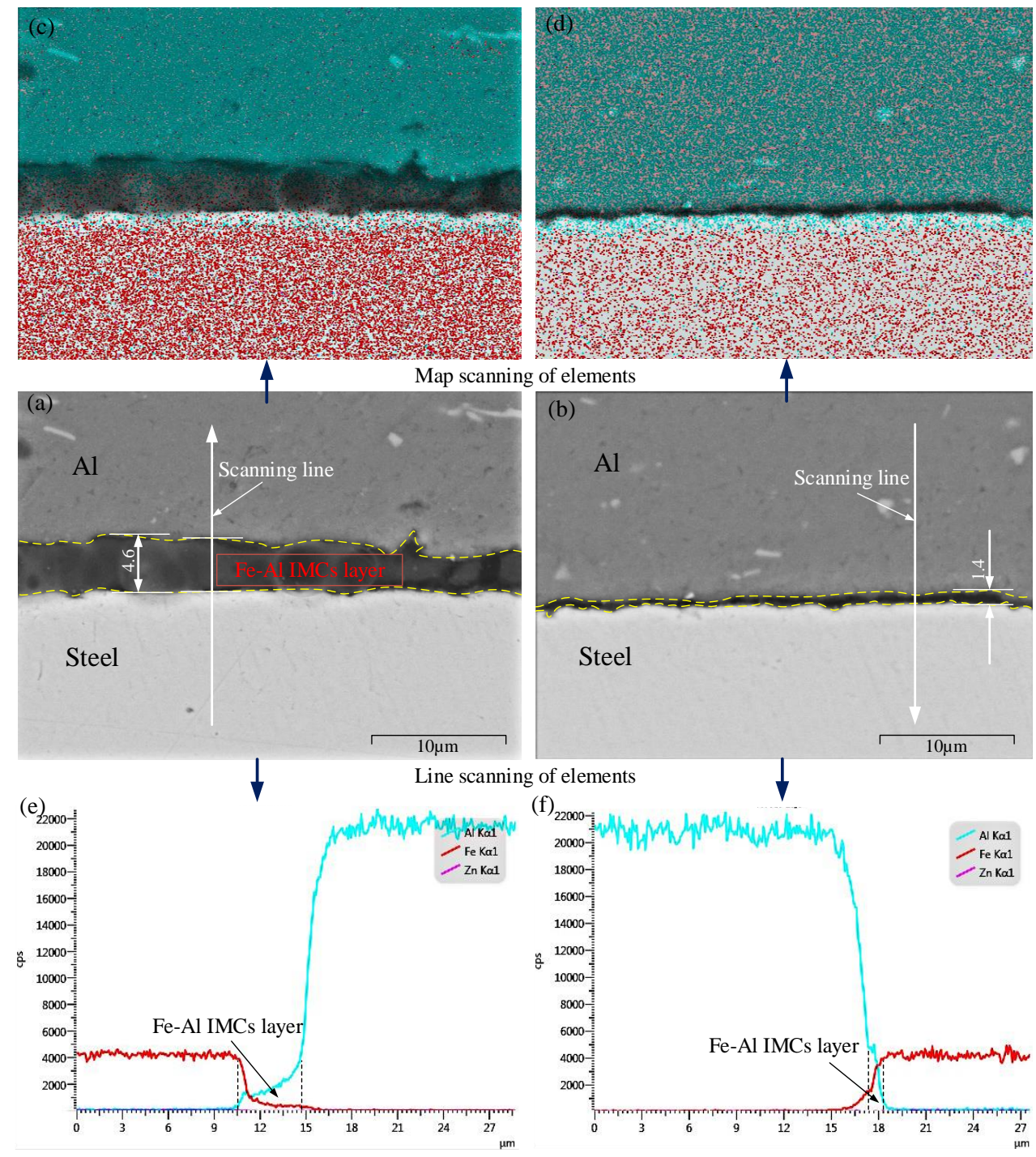

Figure 3. Magnified SEM views and EDS analysis results of region A: (a,c,e) without Zn interlayer; $(\mathbf{b}, \mathbf{d}, \mathbf{f})$ with $0.1 \mathrm{~mm} \mathrm{Zn}$ interlayer.

Region B of the Zn-added joint marked in Figure 2 is selected to analyze the interface microstructure under HAZ, as shown in Figure 4. The maximum thickness of the diffusion layer in region B reaches $17.9 \mu \mathrm{m}$. The delamination phenomenon of diffusion layer exists. The Al-based solid solution and the granular Al-Zn eutectic are formed in the upper part of diffusion layer near the aluminum alloy side, and the lower layer near the steel side is made up of Fe-Zn IMCs, as shown in Figure 4a. Part of liquid Zn in region B under HAZ is still reserved due to the insufficient extruded effect provided by the tool, which causes a thicker diffusion layer than that of region A. Compared to region $\mathrm{A}$, the diffusion layer in 
region B has a different structure and composition. During the FSLW process, some small size aluminum particles may separate from the aluminum alloy under the action of strong material flow, and then fall into the liquid $\mathrm{Zn}$ at the lap interface. According to the binary phase diagram of $\mathrm{Al}-\mathrm{Zn}$, the eutectic temperature of $\mathrm{Al}$ and $\mathrm{Zn}$ is about $381{ }^{\circ} \mathrm{C}$, which is lower than the melting point of $\mathrm{Zn}$. Moreover, the distribution density of $\mathrm{Al}$ element is higher than that of $\mathrm{Zn}$ element, as shown in Figure $4 \mathrm{~b}$,c. Therefore, the upper part of diffusion layer near the aluminum alloy side is mainly composed of the Al-based solid solution and the granular Al-Zn eutectic. At the same time, there are discontinuous Fe- $\mathrm{Zn}$ IMCs near the lap interface of steel side. Due to the barrier of $\mathrm{Zn}$ interlayer, it is difficult to form atomic diffusion between $\mathrm{Fe}$ and $\mathrm{Al}$ elements at region $\mathrm{B}$, which makes the lower part of diffusion layer mainly form Fe-Zn IMCs rather than Fe-Al IMCs near the steel side.
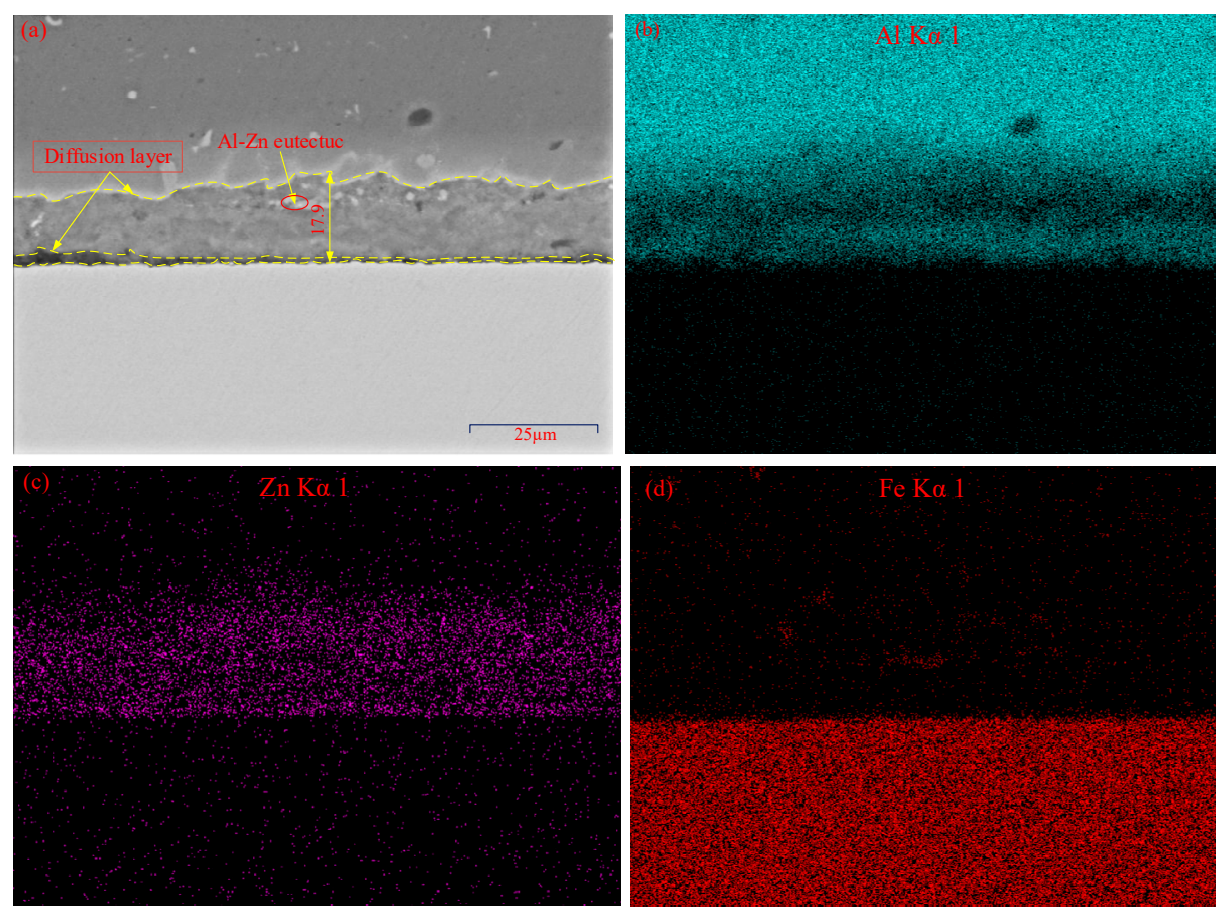

Figure 4. (a) Magnified SEM view of region B; (b-d) area scanning results of (a).

Figure 5 show the magnified SEM view of region $C$ and the corresponding area scanning results by EDS. It is found that the diffusion layer is much thicker than that of region $A$ and $B$, and the maximum thickness is $228.6 \mu \mathrm{m}$, as shown in Figure 5a. Under the extruding effect of the stirring tool, the massive liquid $\mathrm{Zn}$ accumulates from region $\mathrm{A}$ to region $\mathrm{C}$. Therefore, most $\mathrm{Zn}$ elements cannot completely react with $\mathrm{Al}$ and Fe elements. As a result, the diffusion layer is greatly thickened. Meanwhile, the delamination phenomenon of diffusion layer in region $C$ also exists, which is similar to that of region $B$. According to the area scanning results by EDS in Figure $5 b-d$, the upper part of diffusion layer near the aluminum side mainly consists of $\mathrm{Zn}$ element due to the $\mathrm{Zn}$ accumulation. Meanwhile, there are some aluminum particles in the $\mathrm{Zn}$ layer of region $\mathrm{C}$ under the driving of the tool. The crack also appears in the diffusion layer. In addition, the Fe-Zn IMCs layer appears on the upper surface of steel sheet. The region $C$ is still at a relatively high temperature state, and the liquid $\mathrm{Zn}$ inhibits the combination between $\mathrm{Al}$ and Fe elements, so Fe- $\mathrm{Zn}$ IMCs are produced. This phenomenon also shows that the effective diffusion bonding in the interface of region $C$ is achieved. Compared with region $B$, region $C$ has the smaller thickness of Fe-Zn IMCs layer because the temperature during welding decreases with increasing the distance away from the SZ. 

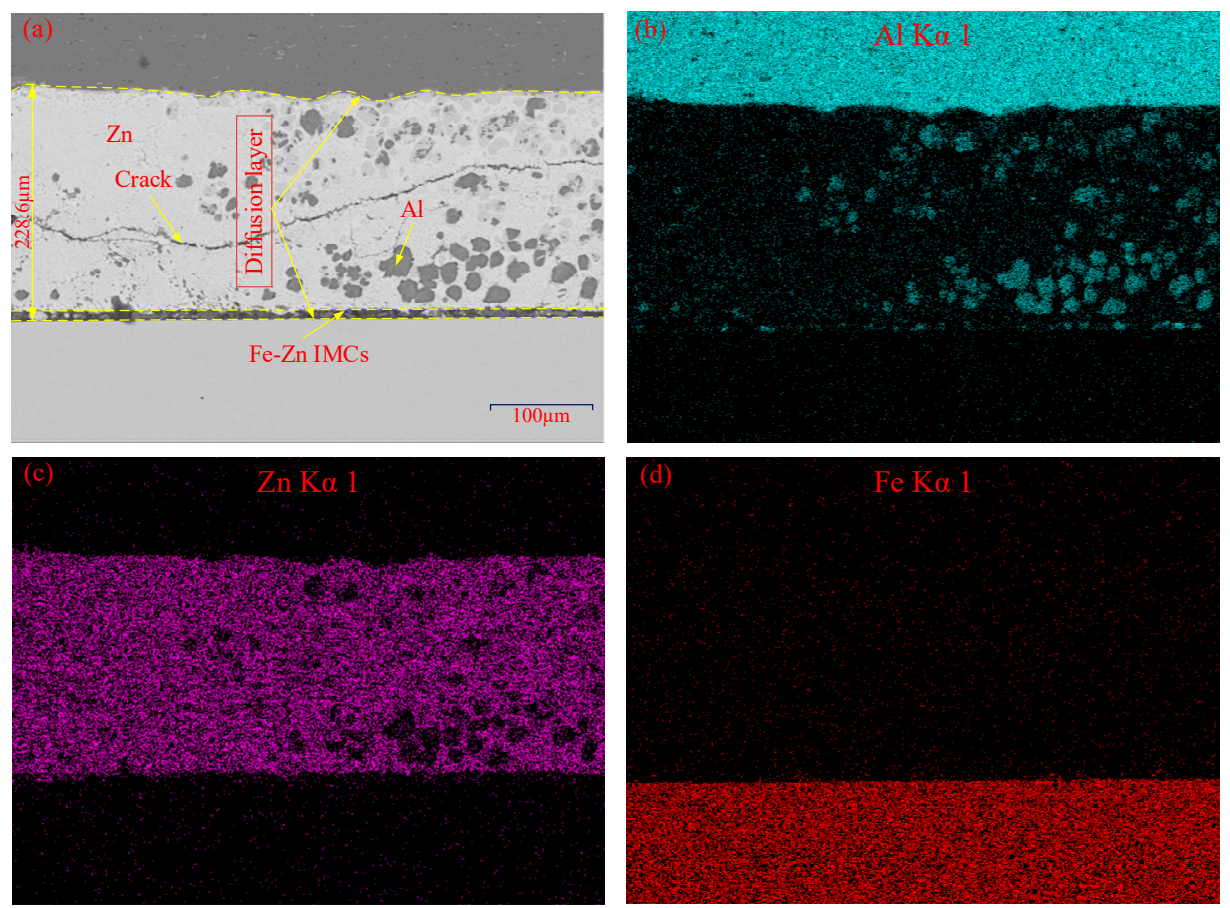

Figure 5. (a) Magnified SEM views of region $C$ with $0.1 \mathrm{~mm} \mathrm{Zn}$ interlayer; (b-d) area scanning results of (a).

\subsection{Mechanical Properties}

The microhardness distributions of the two joints are presented in Figure 6, and the positions of measured points are shown in Figure 2. The microhardness of steel is nearly equal to that of BM $(232 \mathrm{HV})$, which reveals that the welding heat input during FSLW has almost no effect on the steel material when the tool pin not penetrating the steel sheet. In the vertical direction (Figure 6a), the middle-measured point is located at the lap interface, and the diagonal diameter of indentation is $50 \mu \mathrm{m}$, so the microhardness of this point has the value higher than that of aluminum BM $(72 \mathrm{HV})$ and smaller than that of steel BM. In Figure 6a, three measured points are located at the SZ and have the smaller microhardness than that of aluminum BM. Figure $6 \mathrm{~b}$ displays the microhardness distributions along the direction parallel to the lap interface. It is known that the microhardness distributions and values of the two joints are similar, and the two distributions both basically present a " $\mathrm{W}$ " shape. However, the HAZ of the Zn-added joint is narrower than that of the Zn-not-added joint, indicating that the $\mathrm{Zn}$ interlayer absorbs the welding heat during FSLW. The hardness of BM is the highest, and SZ, TMAZ and HAZ owns the smaller microhardness than BM, because the aluminum alloy used in this study is a kind of heat-treated reinforced aluminum alloy [31]. Compared with other zones, SZ has a relatively higher microhardness value due to the finer grains induced by the dynamic recrystallization, which has been reported by many researchers $[11,32]$ and can be explained by the Hall-Petch formula $[31,33]$.

The tensile shear load-displacement of specimens are shown in Figure 7. It can be concluded that the mean tensile load of the $\mathrm{Zn}$-not-added joint is $4.43 \mathrm{kN}$, and that of the $\mathrm{Zn}$-added joint is $6.26 \mathrm{kN}$, which is significantly increased by $41.3 \%$. Compared to the tensile shear property of other studies $[15,16,21,34]$, the tensile shear load of the $\mathrm{Zn}$-added joint in this study still belongs to the high value. The addition of $0.1 \mathrm{~mm}$ thick $\mathrm{Zn}$ interlayer improves the interface bonding, and then strengthens the load resistance of the joint. The two joints both exhibit interfacial shear fracture, and their fracture paths are shown in Figure 8.

The AS of aluminum sheet is under the tensile load, and the edge of overlapping area becomes the origin of cracks. In Figure 8a,b, cracks propagate along the lap interface. The larger microhardness difference exists between the diffusion layer and steel, which is easier to induce the greater stress concentration. Therefore, according to the microscopic fracture 
diagram in Figure 8c,d, the IMCs layers at the bottom of diffusion layer peel off from the steel side, causing the shear failure. For the Zn-not-added joint, the Fe-Al IMCs layer at the bottom of diffusion layer peels off from the steel side. For the Zn-added joint, it can be further analyzed by combining the interface microstructures and joint tensile properties. In the center of the welding spot (region A), the Fe-Al IMCs layer still peels off from the steel side. However, in the zones which are away from the center of the joint (regions B and C) of the $\mathrm{Zn}$-added joint, the compositions at the bottom of diffusion layer which is peeled off from the steel changes from Fe-Al IMCs to Fe-Zn IMCs. Compared with Fe-Al IMCs layer with steel, the Fe-Zn IMCs layer has a stronger bonding with the steel. In fact, the tensile shear load of the Zn-added joint is bigger than that of the Zn-not-added joint, as shown in Figure 7. The phenomena reveal that the modification of microstructure and composition of the $\mathrm{Zn}$-added joint is beneficial to increasing the tensile shear property. In fact, the $\mathrm{Zn}$ thickness, the rotating speed, the welding speed, and the plunging depth all influence the mechanical property of the $\mathrm{Al} /$ Steel joint, and these influencing factors are interactive and complex. Therefore, the DOE method such as Zuo et al. [35] and Chitturi et al. [36] can be used to further enhance and then maximize the $\mathrm{Al} /$ steel joint strength in the future.
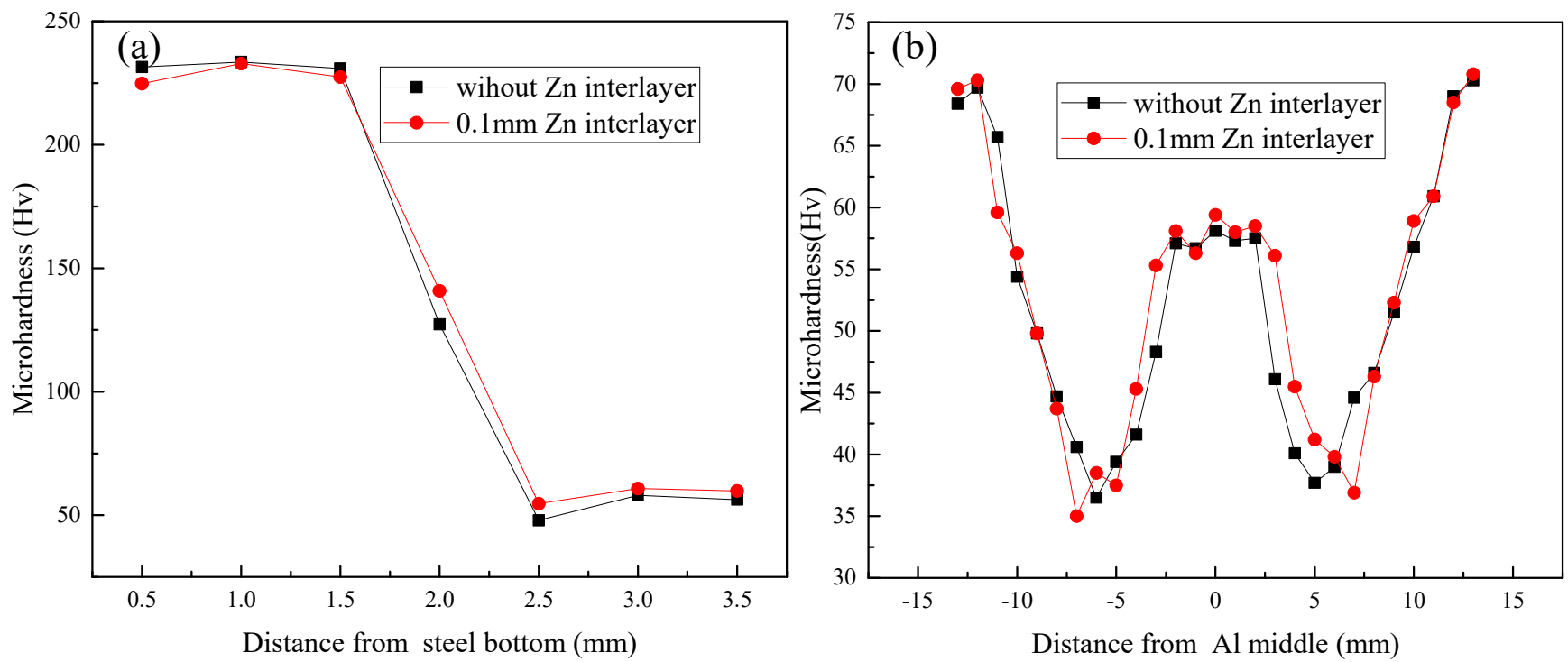

Figure 6. Microhardness distribution of joints along the vertical direction (a) and horizontal direction (b).

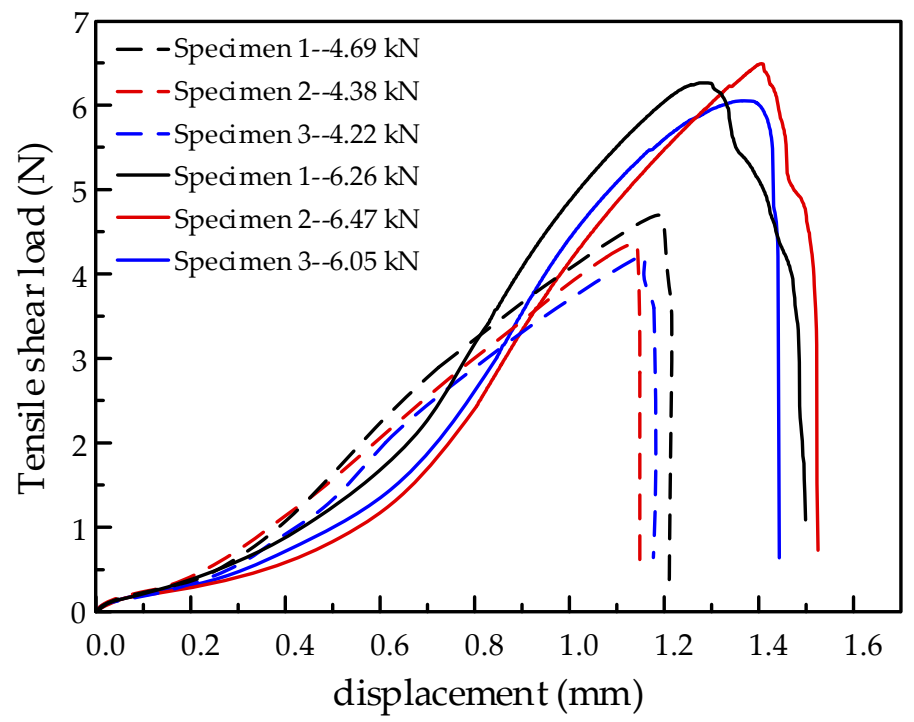

Figure 7. Tensile shear load-displacement of specimens. 


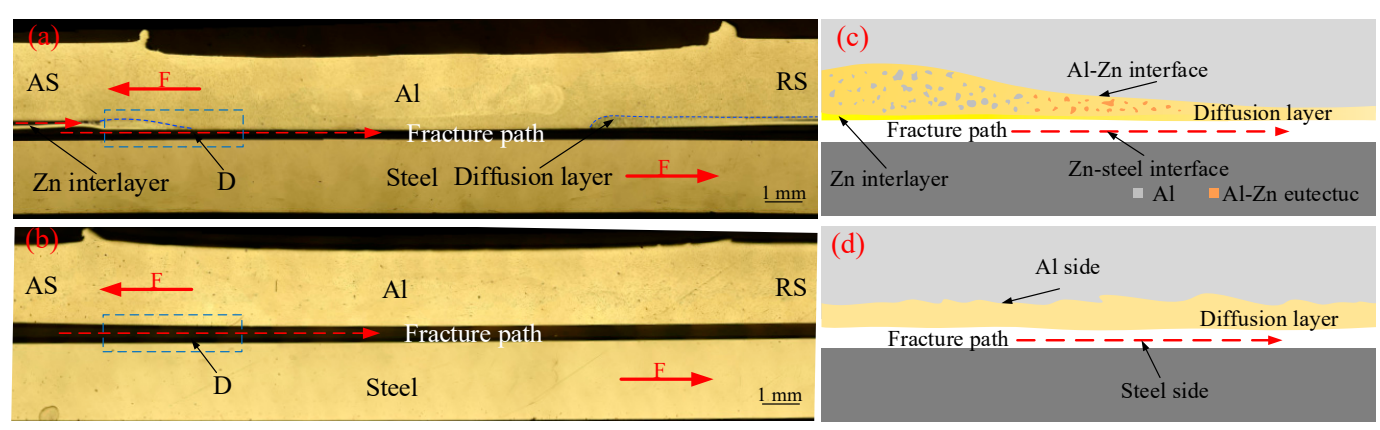

Figure 8. The fractured joints and the enlarged schematic views of region D marked in the fractured joint: with $0.1 \mathrm{~mm} \mathrm{Zn}$ interlayer (a,c); without Zn interlayer $(\mathbf{b}, \mathbf{d})$.

\section{Conclusions}

The Al-Mg-Si alloy and 301L steel were successfully diffusion bonded by FSLW assisted by the $\mathrm{Zn}$ interlayer. The relationships between the lap interface structure and the mechanical properties of the joint were discussed. The following conclusions are extracted.

(1) The diffusion layer between the aluminum and steel sheets was changed from the continuous distribution to the uneven and segmented distribution. Compared to the single Fe-Al IMCs in the diffusion layer of the Zn-not-added joint, the Fe-Zn IMCs and Al-Zn eutectic are formed in the Zn-added joint. When a $0.1 \mathrm{~mm}$ thick $\mathrm{Zn}$ interlayer was adopted, the uneven and segmented diffusion layer owned the significantly changed thickness and compositions.

(2) The tensile shear load of the $\mathrm{Zn}$-added joint was $6.26 \mathrm{kN}$, presenting an obvious increase of $41.3 \%$ compared with the Zn-not-added joint. These two joints presented the shear fracture along the lap interface, and the diffusion layers both peel off from the steel side. The heightened tensile shear strength by adding $\mathrm{Zn}$ interlayer mainly resulted from the rationally reduced and modified diffusion layer.

Author Contributions: Methodology, S.-D.J. and D.-J.Y.; analysis, J.-H.D. and H.L.; investigation, H.-X.Z.; data curation, H.L.; writing-original draft preparation, J.-H.D., H.L. and H.-X.Z.; writing-review and editing, S.-D.J. and D.-J.Y., H.L. and J.-H.D. contributed equally to this work. All authors have read and agreed to the published version of the manuscript.

Funding: This research was funded by National Natural Science Foundation of China (No. 51874201) and the Guangdong Special Branch Plans (2019TQ05C752).

Institutional Review Board Statement: Not applicable.

Informed Consent Statement: Not applicable.

Data Availability Statement: The raw data required to reproduce these results cannot be shared at this time as the data also forms part of an ongoing study.

Conflicts of Interest: The authors declare no conflict of interest.

\section{References}

1. Granum, H.; Myhr, O.R.; Brvik, T.; Odd, S.H. Effect of pre-stretching on the mechanical behaviour of three artificially aged 6xxx series aluminium alloys. Mater. Today Commun 2021, 27, 102408. [CrossRef]

2. Sun, X.; Zhang, Q.; Wang, S.; Han, X.; David, S.A. Effect of adhesive sealant on resistance spot welding of 301L stainless steel. J. Manuf. Process. 2020, 51, 62-72. [CrossRef]

3. Kaushik, P.; Dwivedi, D.K. Effect of tool geometry in dissimilar Al-Steel Friction Stir Welding. J. Manuf. Process. 2020, 68, 198-208. [CrossRef]

4. $\quad$ Liu, J.L.; Hao, Z.L.; Xie, Y.M.; Meng, X.C.; Huang, Y.X.; Wan, L. Interface stability and fracture mechanism of Al/Steel friction stir lap joints by novel designed tool. J. Mater. Process. Technol. 2022, 300, 117425. [CrossRef]

5. Alhazaa, A.; Haneklaus, N. Diffusion bonding and transient liquid phase (TLP) bonding of type 304 and 316 austenitic stainless steel-a review of similar and dissimilar material joints. Metals 2020, 10, 613. [CrossRef]

6. Hasanniah, A.; Movahedi, M. Gas tungsten arc lap welding of aluminum/steel hybrid structures. Mar. Struct. 2019, 64, 295-304. [CrossRef] 
7. Js, A.; Ksa, B.; Dks, A. Lap weld-brazing of aluminum to steel using novel cold metal transfer process. J. Mater. Process. Technol. 2020, 283, 116728

8. Florence, P.L.; Narayanaswamy, K.S.; Sai, P.; Devaraj, S. Impact of friction stir welding tool profile on the strength of dissimilar aluminum and stainless steel welded joints. Mater. Today Proc. 2021, 46, 583-585. [CrossRef]

9. Yasui, T.; Tian, W.B.; Hanai, A.; Mori, T.; Fukumoto, M. Friction stir girth welding between aluminum and steel rods. Procedia Manuf. 2018, 15, 1376-1381. [CrossRef]

10. Yasui, T.; Tian, W.B.; Hanai, A.; Mori, T.; Fukumoto, M. Mechanism of intermetallic compound formation during the dissimilar friction stir welding of aluminum and steel. J. Mater. Sci. 2020, 55, 3064-3072.

11. Wan, L.; Huang, Y.X. Microstructure and mechanical properties of Al/steel friction stir lap weld. Metals 2017, 7, 542. [CrossRef]

12. Huang, Y.X.; Meng, X.C.; Xie, Y.M.; Wan, L.; Lv, Z.L. Friction stir welding/processing of polymers and polymer matrix composites. Compos. Part A 2018, 105, 235-257. [CrossRef]

13. Huang, Y.X.; Wan, L.; Meng, X.C.; Xie, Y.M.; Lv, Z.L.; Zhou, L. Probe shape design for eliminating the defects of friction stir lap welded dissimilar materials. J. Manuf. Process. 2018, 35, 420-427. [CrossRef]

14. Pourali, M.; Abdollah-Zadeh, A.; Saeid, T.; Kargar, F. Influence of welding parameters on intermetallic compounds formation in dissimilar steel/aluminum friction stir welds. J. Alloys Compd. 2017, 715, 1-8. [CrossRef]

15. Kar, A.; Vicharapu, B.; Morisada, Y.; Fujii, H. Elucidation of interfacial microstructure and properties in friction stir lap welding of aluminium alloy and mild steel. Mater. Charact. 2020, 168, 110572. [CrossRef]

16. Mahto, R.P.; Kumar, R.; Pal, S.K.; Panda, S.K. A comprehensive study on force, temperature, mechanical properties, and micro-structural characterizations in friction stir lap welding of dissimilar materials (AA6061-T6 \& AISI304). J. Manuf. Process. 2018, 31, 624-639.

17. Sr, A.; Rkrs, B.; Klak, A. Artificial intelligent approach for process parameters modeling of friction stir processing. Mater. Today Proc. 2021, 43, 326-334.

18. Taher, A.S.; Mohamed, A.; Ammar, H.E.; Zhou, J.X. Modeling of friction stir welding process using adaptive neuro-fuzzy inference system integrated with harris hawks optimizer. J. Mater. Res. Technol. 2019, 8, 5882-5892.

19. Waheed, S.; Mohamed, A.E.; Emad, I.G.; Essam, B.M.; Ammar, H.E. A new fine-tuned random vector functional link model using hunger games search optimizer for modeling friction stir welding process of polymeric materials. J. Mater. Res. Technol. 2021, 14, 1482-1493.

20. Kumar, M.; Das, A.; Ballav, R. Influence of interlayer on microstructure and mechanical properties of friction stir welded dissimilar joints: A review. Mater. Today Proc. 2020, 26, 2123-2129. [CrossRef]

21. Zheng, Q.; Feng, X.; Shen, Y.; Huang, G.; Zhao, P. Dissimilar friction stir welding of $6061 \mathrm{Al}$ to 316 stainless steel using Zn as a filler metal. J. Alloys Compd. 2016, 686, 693-701. [CrossRef]

22. Ahmed, E.; Makoto, T.; Kenji, I. Friction-stir-welded lap joint of aluminum to zinc-coated steel. Q. J. Jpn Weld. Soc. 2005, 23, 186-193.

23. Akca, E.; Gursel, A. The importance of interlayers in diffusion welding-A review. Period. Eng. Nat. Sci. 2015, 3, 12-16. [CrossRef]

24. Li, W.Y.; Liu, J.F.; Zhang, Z.H.; Gao, D.L.; Wang, W.B. Improving mechanical properties of pinless friction stir spot welded joints by eliminating hook defect. Mater. Des. 2014, 62, 247-254. [CrossRef]

25. Huang, Y.X.; Wan, L.; Si, X.Q.; Huang, T.F.; Meng, X.C.; Xie, Y.M. Achieving high-quality Al/Steel joint with ultrastrong interface. Metall. Mater. Trans. A 2019, 50, 295-299. [CrossRef]

26. Haghshenas, M.; Abdel-Gwad, A.; Omran, A.M.; Goekce, B.; Sahraeinejad, S.; Gerlich, A.P. Friction stir weld assisted diffusion bonding of 5754 aluminum alloy to coated high strength steels. Mater. Des. 2014, 55, 442-449. [CrossRef]

27. Mahto, R.P.; Bhoje, R.; Pal, S.K.; Joshi, H.S.; Das, S. A study on mechanical properties in friction stir lap welding of AA 6061-T6 and AISI 304. Mater. Sci. Eng. A 2016, 652, 136-144. [CrossRef]

28. Ratanathavorn, W.; Melander, A. Influence of zinc on intermetallic compounds formed in friction stir welding of AA5754 aluminum alloy to galvanised ultra-high strength steel. Sci. Technol. Weld. Join. 2017, 22, 673-680. [CrossRef]

29. Movahedi, M.; Kokabi, A.H.; Reihani, S.M.S.; Cheng, W.J.; Wang, C.J. Effect of annealing treatment on joint strength of aluminum/steel friction stir lap weld. Mater Des. 2013, 44, 487-492. [CrossRef]

30. Movahedi, M.; Kokabi, A.H.; Reihani, S.M.S.; Najafi, H. Effect of tool travel and rotation speeds on weld zone defects and joint strength of aluminum steel lap joints made by friction stir welding. Sci. Technol. Join. 2012, 17, 162-167. [CrossRef]

31. Suresh, S.; Venkatesan, K.; Natarajan, E.; Rajesh, S.; Lim, W.H. Evaluating weld properties of conventional and swept friction stir spot welded 6061-T6 aluminium alloy. Mater. Express 2019, 9, 851-860. [CrossRef]

32. Shen, Z.; Yang, C.; Haghshenas, M.; Gerlich, A.P. Role of welding parameters on interfacial bonding in dissimilar steel/aluminum friction stir welds. Eng. Sci. Technol. Int. J. 2015, 18, 270-277. [CrossRef]

33. Zuo, Y.Y.; Liu, H.; Gong, P.; Ji, S.D.; Wu, B.S. Radial additive friction stir repairing of mechanical hole out of dimension tolerance of AZ31 magnesium alloy assisted by stationary shoulder: Process and mechanical properties. Acta Metall. Sin. Engl. Lett. 2021, 34, 1345-1360. [CrossRef]

34. Boumerzoug, Z.; Helal, Y. Friction stir welding of dissimilar materials aluminum Al6061-T6 to ultralow carbon steel. Metals 2017, 7, 42. [CrossRef]

35. Zuo, Y.Y.; Kong, L.P.; Liu, Z.L.; Lv, Z.; Wen, H.J. Process parameters optimization of refill friction stir spot welded $\mathrm{Al} / \mathrm{Cu}$ joint by response surface method. Trans. Indian Inst. Met. 2020, 73, 2975-2984. [CrossRef]

36. Chitturi, V.; Pedapati, S.R.; Awang, M. Effect of tilt angle and pin depth on dissimilar friction stir lap welded joints of aluminum and steel alloys. Materials 2019, 12, 3901. [CrossRef] [PubMed] 